\title{
The Efficacy of Written Corrective Feedback and Language Analytic Ability on Chinese Learners' Explicit and Implicit Knowledge of English Articles
}

\author{
Lin Jiang $^{1} \&$ Hailing Xiao ${ }^{1}$ \\ ${ }^{1}$ Faculty of English Language and Culture, Guangdong University of Foreign Studies, China \\ Correspondence: Lin Jiang, Faculty of English Language and Culture, Guangdong University of Foreign Studies, \\ Guangzhou, Guangdong, 510420, China. E-mail: jlin@gdufs.edu.cn
}

Received: July 16, 2014 Accepted: August 26, 2014 Online Published: September 22, 2014

doi:10.5539/elt.v7n10p22 URL: http://dx.doi.org/10.5539/elt.v7n10p22

\begin{abstract}
This article reports on an 8-week study that investigated the differential effects of two written corrective feedback (CF) options on 92 low-intermediate EFL students' explicit and implicit knowledge of English articles and the extent to which language analytic ability might influence the effect of written CF. The study used a pretest-treatment-posttest-delayed posttest design with three groups: a direct-only correction (DOC) group, a direct metalinguistic correction (DMC) group, and a control group. The acquisition of explicit knowledge was measured by an error correction test, and implicit knowledge was measured by a picture-cued writing test. It was found that both the DOC and the DMC benefited explicit and implicit knowledge, but no significant differences were reported in their effects on each type of knowledge. This study also showed that language analytic ability mediated the effectiveness of the DOC rather than that of the DMC. These findings are discussed from the perspective of cognitive psychology and implications and suggestions for further research are put forward.
\end{abstract}

Keywords: English articles, explicit knowledge, implicit knowledge, language analytic ability, written corrective feedback

\section{Introduction}

Research on written corrective feedback (CF), also known as "error/grammar correction", is an area that both foreign language teachers and second language acquisition (SLA) researchers are concerned about. In first language and second language (L2) acquisition theories, there have been divergent views on the role of written $\mathrm{CF}$ and the attitudes towards its value have experienced several phases of changes in history. In the 1950s and 1960s, under the influence of behaviorist perspectives of language learning that emphasized habit-forming, errors were seen to interfere with the learning process and so should be prevented from occurring. In the 1970s and 1980s, under the influence of nativist views about language learning, acquisition was considered to be driven by positive evidence and negative evidence like CF to be useless at all. More recently, under the influence of interactionist theories of language learning, errors were viewed as treatable through the feedback that occurs naturally in interaction (Sheen, 2010a). Since Truscott's (1996) article in Language Learning, in which he claimed there was neither any empirical nor theoretical justification for written error correction, a growing number of empirical studies as well as theoretical discussions on the efficacy of written CF have been aroused over the past 15 years.

"The implicit/explicit issue lies at the heart of the debate about the efficacy of error correction, and, also perhaps can help explain a misunderstanding about what this debate is actually about" (Shintani \& Ellis, 2013, p. 287). In a series of articles (e.g., Truscott, 1999, 2004, 2007, 2010) Truscott continued to reject any role for error correction. The nub of his argument is that error correction will not be useful for acquisition of the type of knowledge needed to engage in writing or speaking for communicative purposes-i.e. implicit knowledge, because it is infeasible to provide written CF at a time when the learner is "ready" to acquire a particular form or structure. However, he acknowledged that written CF could have an impact on explicit knowledge needed for monitoring in grammar tests or editing a written text that has been corrected. In the meantime, other researchers were also of the view that error feedback contributes to explicit rather than implicit knowledge (e.g. Bitchener, 2012; Polio, 2012). In fact, all that we do know is that written error correction leads to improved accuracy in 
writing. We do not know whether this is because it benefits explicit knowledge or implicit knowledge for, as Polio (2012) put forward, learners can use both types of knowledge when writing under no time pressure. There have been very few studies to date that have attempted to investigate whether written CF assists the development of explicit knowledge, the acquisition of implicit knowledge or both (Shintani \& Ellis, 2013).

In contrast, there is now ample empirical evidence that oral CF causes improved linguistic accuracy in oral spontaneous production (see Li, 2010, for a review of the relevant studies), which provides the best evidence that acquisition of implicit knowledge has occurred. However, given the differences in the nature of written and oral feedback (see Sheen, 2010b, for an analysis of the differences), it cannot be assumed that the former will have the same effect as the latter until further research is conducted. Thus, the present study intends to fill that gap by investigating the relative effectiveness of two written CF options on learners' explicit and implicit L2 knowledge of English articles, which may contribute to the existing literature on error correction, both theoretically and empirically.

\section{Background Literature}

\subsection{The Effectiveness of Written $C F$}

To date, we still cannot provide unambiguous evidence of the role of written CF in the SLA process. A major reason we identified for this is that the previous studies differed in how they measured the efficacy of written CF (Sheen, 2007). Some studies have measured improvement only by examining learner's revised texts (Ashwell, 2000; Fathman \& Whalley, 1990; Ferris, 2006; Ferris \& Roberts, 2001; Truscott \& Hsu, 2008). Their findings confirm that "correction does help students reduce their errors on the writing on which they receive the corrections, and that the effect is substantial" (Truscott \& Hsu, 2008, p. 299). One could argue, however, as Truscott $(1996,2007$; Truscott \& Hsu, 2008) consistently did, that ability to use feedback to improve an existing text does not mean that learning has occurred in the long run. To claim that error correction truly makes students more successful writers, longitudinal studies of written $\mathrm{CF}$ which examine learners' production of new texts after receiving feedback are rather important.

Truscott's argument provoked a number of longitudinal studies of the effects of written CF in L2 writing classroom (e.g., Chandler, 2003; Ferris, 2006; Foin \& Lange, 2007). In fact, this set of studies is messier, more problematic, and more difficult to interpret than the revision studies (Bitchener \& Ferris, 2012). For example, in most of the studies, a no-feedback control group was not included in the design and the absence of a control group makes it hard to argue that written CF alone led to any measurable improvements. Secondly, student progress in written accuracy over time was not always consistent or linear. Given these limitations, caution is needed in interpretation of the results of some written CF studies conducted by L2 writing researchers which showed that the students who received error feedback made at least some progress in written accuracy over time.

By comparison, studies of written CF conducted by SLA researchers were carried out under far more controlled experimental conditions (e.g., Bitchener \& Knock, 2008; Bitchener, Young, \& Cameron, 2005; Sheen, 2007; Shintani \& Ellis, 2013). They focused on a few carefully chosen and defined error types (e.g., some functional uses of the English article system and the use of the simple past tense), and provided feedback systematically. As a body of work, they reported robust evidence that written CF, under the right conditions, can facilitate L2 development, suggesting that there may be value both in teachers' continuing to provide written CF if it is done carefully and in making further efforts to design studies that address some of the unresolved questions.

\subsection{Written $C F$ and Explicit/Implicit L2 Knowledge}

While there is now evidence to show that written CF caused improved accuracy over time, it is not clear whether this is because of effect it has on explicit or implicit knowledge in that learners can use both types of knowledge when writing without time pressure (Polio, 2012). The role of written error correction in the development of explicit and implicit knowledge, on a theoretical level, has been controversial. Some researchers take the position that written $\mathrm{CF}$ which is inevitably explicit in nature will only facilitates the development of explicit knowledge (e.g., Krashen, 1982; Schwartz, 1993; Truscott, 1996). This position is compatible with the no-interface position which states that there is an absolute separation of explicit and implicit knowledge inside speakers' minds. However, others argue that since explicit knowledge will develop gradually into implicit knowledge when learners are exposed to more L2 input and opportunities for production, written CF may indirectly contribute to the development of implicit knowledge (e.g., N. Ellis, 2005; R. Ellis, 1993). This position is compatible with the weak-interface hypothesis which states that explicit knowledge can become implicit to some extent, but that these are limited by various developmental factors. Clearly, the only way an attempt can be made to resolve the various claims is by means of empirical investigation. 
Acknowledging that the existence of explicit and implicit knowledge is generally accepted in SLA, Williams (2012) pointed out that the crucial issue was whether error correction simply encourages learners to activate their explicit knowledge or whether it also benefits their implicit knowledge. Bitchener (2012) was similarly concerned about whether error correction had any impact on implicit knowledge. Polio (2012, p. 408) argued that "establishing a research agenda on the roles of explicit and implicit knowledge in writing is crucial". In spite of the importance of this area, however, empirical evidence remains sparse.

Shintani and Ellis (2013), an exception, has specifically addressed the effects of written CF on explicit and implicit knowledge. This study compares the effect of direct written $\mathrm{CF}$ and metalinguistic explanation on learners' explicit and implicit knowledge of the English indefinite article. It was found that the direct written CF facilitated neither explicit nor implicit knowledge, while the metalinguistic explanation promoted the development of explicit knowledge but the effect was not durable, and it had no effect on implicit knowledge. However, the feedback in this study was quite limited involving very few corrections for some individual learners, so it would clearly be premature to rule out the possibility that feedback can impact on implicit knowledge as claimed by some researchers. To sum up, the controversy about whether or not written CF can facilitate the development of implicit knowledge and the lack of empirical evidence call for more research to be carried out into this issue.

The distinction between explicit and implicit knowledge is a central issue in SLA research. Ellis (2004) has drawn seven criteria to distinguish the two types of knowledge, namely, degree of awareness, time available, focus of attention, systematicity, certainty, metalanguage, and learnability. According to these criteria, implicit knowledge is defined as unconscious, intuitive, procedural knowledge concerning what is grammatical, and can be retrieved within limited time, whereas explicit knowledge is claimed to denote a conscious awareness of grammatical rules and the appropriate metalanguage that can be verbalized by individuals (Ellis, 2004). Drawing on the above criteria, it is possible to design tests which tap into learners' explicit and implicit knowledge respectively. Ellis (2005) argued that tests of implicit knowledge need to prompt learners to use language by feel under the constraint of time and focus on meaning, whereas tests tapping explicit knowledge should elicit a test performance where learners are encouraged to apply grammatical rules without time pressure, and focus on form consciously.

\subsection{Studies of Direct Written $C F$}

Over the years, the pedagogically driven question about whether some types of written CF are more effective than others has received more research attention than any other question. This is understandable given the desire of teachers to know whether they might more profitably spend their time providing one type of feedback rather than another type. Studies that have made these comparisons have most often categorized the feedback options as direct or indirect. This study focused exclusively on direct feedback, which has been defined as follows:

Direct feedback provides some form of explicit correction of linguistic form or structure above or near the linguistic error and usually involves the crossing out of an unnecessary word /phrase /morpheme, the insertion of a missing word/phrase/morpheme, and/or the provision of the correct form or structure.

(Bitchener \& Ferris, 2012, p. 65)

More recently, direct feedback has consisted of written metalinguistic information about grammatical rules and examples of target usage and, sometimes, oral form-focused instruction. Some studies have compared the effects of different direct CF strategies on improving learners' linguistic accuracy. Bitchener et al. (2005) examined two types of direct feedback: direct correction in combination with oral metalinguistic explanation in the form of five-minute one-to-one conferences and direct error correction alone. It was reported that there was an advantage for additional metalinguistic explanation over direct error correction alone for L2 acquisition of the past simple tense and the definite article but no effect was found for prepositions. Sheen (2007) examined the relative effectiveness of two direct written CF options (i.e., direct error correction alone, direct error correction in combination with written metalinguistic explanation) on L2 acquisition of English articles. The results showed no difference between the two types of feedback in the immediate posttest, but an advantage for metalinguistic comments over direct correction alone was found in the delayed posttest carried out two months later. While these two studies reported an advantage for direct correction in combination with metalinguistic explanation over direct correction alone, other studies (Bitchener, 2008; Bitchener \& Knoch, 2008, 2010) found no such advantage.

Bitchener (2008) compared the effects of four written CF types (i.e., direct CF with written and oral metalinguistic comments, direct $\mathrm{CF}$ with written metalinguistic comments, direct $\mathrm{CF}$, no feedback) on two functional uses of the English article system (the indefinite article "a(n)" for the first mention and the definite 
article "the" for anaphoric reference). It was showed that both the direct CF with written and oral metalinguistic comments group and the direct $\mathrm{CF}$ group outperformed the control group, while the direct CF with written metalinguistic comments group just failed to do so. And when the same four feedback types were reexamined on 144 international and migrant students as in Bitchener and Knoch's (2008) study, no significant differences were found among the three treatment options. This is possibly due to the larger sample size which might wipe off the differences in effectiveness among treatment groups as found in Bitchener's (2008) study. Bitchener and Knoch (2010) corroborate the findings of Bitchener and Knoch (2008). As a 10-month longitudinal study, Bitchener and Knoch (2010) found no significant differences in the effectiveness of the same feedback approaches although the three treatment groups performed much better than the control group.

Overall, a firm conclusion about the extent to which learners who receive written and/or oral metalinguistic explanation are able to increase their level of accuracy more than those who receive direct error correction alone cannot be made at this stage. Further research into this issue is therefore required. Moreover, some previous studies on the relative effectiveness of different types of direct written CF included both oral and written metalinguistic information, which makes it difficult to determine whether the advantage was gained from oral or written metalinguistic explanation, or the combination of both. Therefore, a body of well-designed studies is needed if this key issue is to be resolved.

\subsection{The Mediating Effect of Individual Factors on Written $C F$}

It is common for classroom instructors to find that some learners may benefit more from written CF than others due to individual differences in learning motivation, learning style, language aptitude, working memory, and metalinguistic awareness, etc. Therefore, it is of necessity to take individual factors into consideration so as to better interpret the value of written CF. However, an examination of this issue has not been prominent in the literature, which might be due to the cognitive tradition where group performance is viewed as more important than individual performance (Bitchener, 2012). Sheen (2007), an exception, has examined the extent to which learners' language analytic ability influenced the effectiveness of written CF. Language analytic ability is one of the four constituent abilities of what Carroll (1981) defined as language aptitude. It is termed as "the capacity to infer rules of language and make linguistic generalizations or extrapolations" (Skehan, 1998, p. 207). Sheen (2007) found that learners of higher language analytic ability benefited from written CF treatment to a greater extent than learners of lower language analytic ability. Moreover, compared with direct-only correction, the effectiveness of direct metalinguistic correction was more strongly related to learners' language analytic ability.

We cast doubt upon Sheen's (2007) finding. Direct metalinguistic correction provides learners with metalinguistic explanation as well as corrects linguistic forms. Then it can be assumed that irrespective of learners' language analytic ability, learning effect may occur as long as learners align with the language input provided to them in the form of the correct linguistic forms in combination with metalinguistic explanation. In contrast, direct-only correction provides learners with correct linguistic forms but no metalinguistic explanation, so learners might have relied more on their language analytic ability in order to infer and generalize linguistic rules under such $\mathrm{CF}$ condition. To sum up, it is reasonable to predict that the effectiveness of direct-only correction may be mediated by learners' language analytic ability to a greater extent than that of direct metalinguistic correction, which is obviously inconsistent with Sheen's (2007) result. Thus, this issue needs to be further verified.

\subsection{Research Questions}

In light of the gaps identified in the literature review, the following three research questions motivated the current study:

1) Does written CF have an effect on Chinese learners' acquisition of explicit and implicit knowledge of English articles?

2) Is there any difference in the efficacy that direct-only correction and direct metalinguistic correction have on L2 acquisition of explicit and implicit knowledge of English articles?

3) To what extent does learners' language analytic ability mediate the effectiveness of the two written CF options?

Two major functions of English articles were chosen as the target structure for this study: the use of the indefinite article $a(n)$ for first mention and of the definite article the for subsequent mention, as illustrated in the example below:

Tom bought $a$ car yesterday, but the car was stolen. 


\section{The Study}

\subsection{Participants}

The participants were 98 low-intermediate students from three intact $1^{\text {st }}$-year English classrooms in a junior college in China (Note 1). All participants were Chinese speakers who have learnt English in China for nearly 6 years and they were majoring in tourism professional education. After eliminating students who were absent from any phase of the study, the number of participants reached 92, including 31 male and 61 female students aged 18-22. In the college, they received a two-hour English instruction by the same teacher once a week. The three intact classes were randomly assigned as direct-only correction (DOC) group $(n=29)$, direct metalinguistic correction (DMC) group $(n=31)$, and the control group $(n=32)$.

\subsection{Research Design}

This study adopted a pretest-treatment-immediate posttest-delayed posttest research design. The entire study covered three testing sessions and two treatment sessions, and lasted for a period of eight weeks with a gap of four weeks between the immediate posttest (Posttest 1) and the delayed posttest (Posttest 2) when the three groups followed normal classes. Participants were required to complete the language analytic ability test in week 1. Pretest was administered in week 2. The two treatment sessions took place in week 3 and 4 . Posttest 1 was conducted immediately after the second treatment session. Four weeks later, that is, in week 8 , participants took Posttest 2. There are two subtests in each testing session: an error correction test and a picture-cued writing test.

\subsection{Treatment Procedure}

There are two treatment sessions. In the first session, the two treatment groups received their respective written $\mathrm{CF}$ on picture-cued writing test 1 (applied in pretest) while the control group did not receive any feedback. In the second session, the two treatment groups were instructed to complete picture-cued writing test 2 (not applied in the posttests) and received feedback in the following week while the control group completed the writing test only and did not receive any feedback. Apart from English articles, corrections of other linguistic errors were also given to the treatment groups so as to cover the focus of the study and prevent learners from consciously monitoring the use of articles in the posttests.

The CF treatment involved two direct written CF options. The DOC is operationalized as locating the errors on students' text and providing the correct forms. The DMC consists of indicating the location of an error and the provision of the correct form in combination with written metalinguistic explanation about grammatical rules and examples of target usage.

\subsection{Testing Instruments and Scoring Criteria}

\subsubsection{Error Correction Test}

An error correction test was designed to measure learners' explicit knowledge of English articles. This test consisted of 23 items. There is one and only one error in each item. Learners were instructed to locate the error and make correction without time limit. Among the 23 items, 16 items involve the incorrect use of definite or indefinite articles and the other 7 items were distracters involving the incorrect use of plural, conjunction, subjunctive mood, preposition, adjective or subject-verb agreement. The example below is taken from the test.

*John bought a cake in Haagen-Dazs last Sunday and cake was so expensive.

Learners were assigned one point for each correct suppliance of an article in the 16 obligatory contexts in the test. Distracters were not included in scoring, so the total score for this test was 16 points. Learners' final scores were converted into percentages. The same test was used for the pretest, Posttest 1 , and Posttest 2, but the order of the items was randomly changed from one testing session to another.

\subsubsection{Picture-Cued Writing Test (30 Minutes)}

A time-pressured picture-cued writing test was used to measure learners' implicit knowledge of English articles. This test consisted of 10 sequential pictures, as shown in Figure 1. Students were asked to write a coherent story of at least 150 words based on the pictures. Word prompts were given for each picture to elicit noun phrases with English articles. 


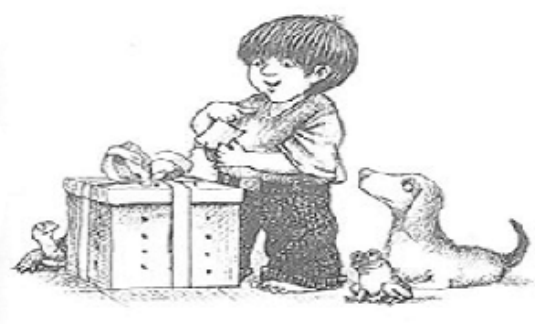

1

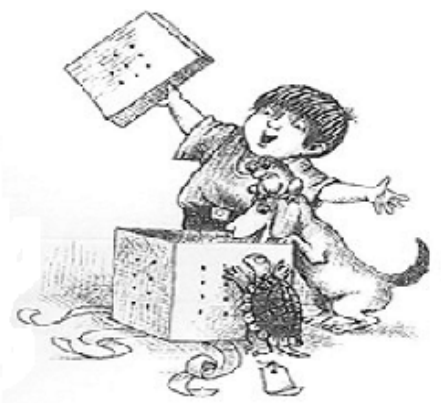

2

Figure 1. Two sample pictures in picture-cued writing test

The Target-Like-Use formula (Pica, 1991) was applied to calculate accuracy of use, as shown in (1). Specifically, all obligatory occasions for the use of 'a(n)' (first mention) and 'the' (subsequent mention) were first identified and each occasion was examined to see whether the correct article had been supplied. Suppliance in non-obligatory contexts was also taken into account as the overuse of articles. The number of correct suppliance in obligatory contexts became the numerator of a ratio, and the denominator was the sum of the number of obligatory contexts for articles and the number of suppliance of articles in non-obligatory contexts.

$n$ correct suppliance in obligatory contexts

$n$ obligatory contexts $+n$ suppliance in non-obligatory contexts $X 100=$ percent accuracy $(1)$

Three different sets of sequential pictures were used for pretest, Posttest 1, and Posttest 2, respectively. A pilot study showed that the three sets of pictures were comparable in the likelihood of eliciting obligatory use of indefinite and definite articles. The rational for using different sets of pictures for the three testing sessions, on the one hand, is to avoid learners' negative reactions to being asked to write the same story for three times; one the other hand, it aims to investigate whether written CF helps learners improve their linguistic accuracy in a new piece of writing, one of the biggest issues in written $\mathrm{CF}$ research.

\subsubsection{Language Analytic Ability Test (20 Minutes)}

This instrument is borrowed from Schmitt, Dornyei, Adolphs, and Durow (2003) to test learners' language analytic ability which is thought to be essential in language learning. There are 14 multiple-choice questions in the test based on a glossary consisting of 6 words and 6 sentences from an imaginary language and their correspondent English translations (see Table 1). For each question there are four choices provided. To make the correct choice, learners need to generalize the linguistic rules based on the grammatical markers supplied in the glossary and then apply the rules to the multiple-choice questions. One point was given for the correct choice in each item with 14 points being the perfect score.

Table 1. Language analytic ability test example (Sheen, 2007, p. 268)

\begin{tabular}{ll}
\hline Imaginary language & English translation \\
\hline Kau & Dog \\
Meu & Cat \\
Kau meud bi & The dog was chasing the cat. \\
Kau meud bo & The dog is chasing the cat. \\
So & Watch \\
Ciu & Mouse \\
Example 1 & \\
The dog is watching the cat. & \\
a. Kau meud so & b. Kau meud si \\
c. Meu kaud so & d. Meu kaud si \\
\hline
\end{tabular}




\subsection{Test Reliability}

In the picture-cued writing test, $25 \%$ of the total data were recoded by a second researcher to examine the reliability of the scoring. The sample was taken equally from pretest, Posttest 1 , and Posttest 2 . The percentage of agreement scores was $84.3 \%, 82.5 \%, 80.9 \%$, respectively, which are satisfactory for the writing test. As for the error correction and language analytic ability tests, internal consistency reliability was estimated by calculating Cronbach's alpha. The reliability coefficient for the error correction pretest was $\alpha=0.81$, and for the language analytic ability test was $\alpha=0.78$.

\subsection{Analysis}

All data were computed using SPSS 16.0 to answer the three research questions. At first, descriptive statistics (including the mean scores and standard deviations) for all the tests were calculated. Then one-way ANOVAs with posthoc Scheffe tests were performed to answer the first and second research questions. Finally, Pearson correlation analyses were employed to address the third research question.

\section{Results}

\subsection{Error Correction Test}

Descriptive statistics for the error correction test are presented in Table 2 and illustrated in Figure 2. It can be seen that both treatment groups showed consistent gains from pretest to the posttests, whereas the control group remained almost the same throughout the testing sessions. One-way ANOVAs with the posthoc tests revealed that there was no significant difference in accuracy rate among the three groups in pretest, $F(2,89)=0.403$, $p>.05$, but significant differences were reported in Posttest $1, F(2,89)=9.402, p<.001$, and Posttest $2, F(2$, $89)=21.015, p<.001$. More specifically, as can be seen in Table 3, in Posttest 1 and 2, both treatment groups performed much better than the control group while no significant difference was found between the two treatment groups.

Table 2. Descriptive statistics for the error correction test

\begin{tabular}{lllllll}
\hline \multirow{2}{*}{ Correction type } & Pretest & \multicolumn{3}{c}{ Posttest 1 } & \multicolumn{3}{c}{ Posttest 2 } \\
\cline { 2 - 7 } & $\mathrm{M}$ & $\mathrm{SD}$ & $\mathrm{M}$ & $\mathrm{SD}$ & $\mathrm{M}$ & $\mathrm{SD}$ \\
\hline DMC group & 0.36 & 0.14 & 0.51 & 0.12 & 0.53 & 0.09 \\
DOC group & 0.32 & 0.19 & 0.46 & 0.17 & 0.47 & 0.13 \\
Control group & 0.35 & 0.14 & 0.37 & 0.10 & 0.37 & 0.10 \\
\hline
\end{tabular}

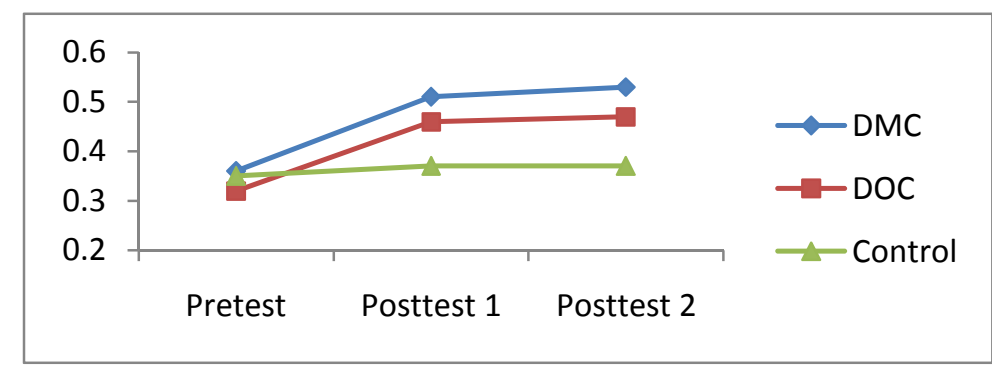

Figure 2. Group means on error correction test

Table 3. Results of scheffe tests for the error correction test

\begin{tabular}{llllllll}
\hline \multirow{2}{*}{$\begin{array}{l}\text { Correction } \\
\text { type }\end{array}$} & $\begin{array}{l}\text { Correction } \\
\text { type }\end{array}$ & Pretest & \multicolumn{3}{c}{ Posttest 1 } & \multicolumn{3}{l}{ Posttest 2 } \\
\cline { 2 - 8 } & MD & $p$ & MD & $p$ & MD & $p$ \\
\hline DMC & DOC & .034 & .678 & .050 & .316 & .060 & .065 \\
DOC & Control & -.023 & .841 & .090 & $.029^{*}$ & .103 & $.001^{* *}$ \\
Control & DMC & -.011 & .961 & -.140 & $.000^{* * *}$ & -.163 & $.000^{* * *}$ \\
\hline
\end{tabular}

Note. ${ }^{*} p<.05,{ }^{* *} p<.01,{ }^{* * *} p<.001$. 


\subsection{Picture-Cued Writing Test}

Descriptive statistics for the picture-cued writing test are presented in Table 4 and illustrated in Figure 3. It can be seen that the three groups all showed consistent gains from pretest to Posttest 1, but slight decrease from Posttest 1 to Posttest 2. One-way ANOVAs with the posthoc tests showed that there was no significant difference in accuracy rate among the three groups in pretest, $F(2,89)=1.185, p>.05$, but significant differences were reported in Posttest $1, F(2,89)=38.078, p<.001$, and Posttest $2, F(2,89)=39.141, p<.001$. More specifically, as can be seen in Table 5, in Posttest 1, both the DOC and the DMC groups performed much better than the control group, and the DMC group also outperformed the DOC group; In Posttest 2, both the DOC and the DMC groups outperformed the control group, and there was no significant difference between the two treatment groups.

Table 4. Descriptive statistics for the picture-cued writing test

\begin{tabular}{lllllll}
\hline \multirow{2}{*}{ Correction type } & Pretest & \multicolumn{3}{c}{ Posttest 1 } & \multicolumn{3}{c}{ Posttest 2 } \\
\cline { 2 - 7 } & $\mathrm{M}$ & $\mathrm{SD}$ & $\mathrm{M}$ & $\mathrm{SD}$ & $\mathrm{M}$ & $\mathrm{SD}$ \\
\hline DMC group & 0.60 & 0.06 & 0.84 & 0.05 & 0.77 & 0.06 \\
DOC group & 0.63 & 0.09 & 0.77 & 0.10 & 0.75 & 0.06 \\
Control group & 0.63 & 0.06 & 0.68 & 0.05 & 0.65 & 0.06 \\
\hline
\end{tabular}

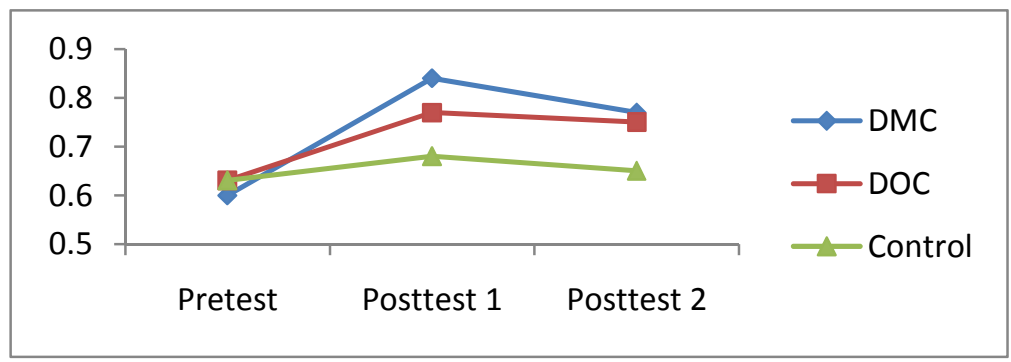

Figure 3. Group means on picture-cued writing test

Table 5. Results of scheffe tests for the picture-cued writing test

\begin{tabular}{llllllll}
\hline \multirow{2}{*}{$\begin{array}{l}\text { Correction } \\
\text { type }\end{array}$} & $\begin{array}{l}\text { Correction } \\
\text { type }\end{array}$ & \multicolumn{2}{l}{ Pretest } & \multicolumn{3}{l}{ Posttest 1 } & \multicolumn{3}{c}{ Posttest 2 } \\
\cline { 2 - 8 } & MD & $p$ & MD & $p$ & MD & $p$ \\
\hline DMC & DOC & -.024 & .373 & .064 & $.002^{* *}$ & .018 & .475 \\
DOC & Control & .003 & .981 & .092 & $.000^{* * *}$ & .103 & $.000^{* * *}$ \\
Control & DMC & .021 & .482 & -.156 & $.000^{* * *}$ & -.121 & $.000^{* * *}$ \\
\hline
\end{tabular}

Note. ${ }^{*} p<.05,{ }^{* *} p<.01,{ }^{* * *} p<.001$.

\subsection{Language Analytic Ability Test}

Table 6 shows the descriptive statistics for the language analytic ability test. The DOC group got the highest score while the DMC group the lowest. However, a one-way ANOVA showed that the differences among groups were not significant, $F(2,89)=2.452, p>.05$. This excludes the possibility that the differences among groups in the posttests were due to the differences in learners' language analytic ability.

Table 7 presents correlations between language analytic ability scores and posttests scores. By examining the correlations between the total scores of the picture-cued writing and error correction tests and the scores for the two separate tests on the one hand and students' language analytic ability scores on the other, it can be seen that the relationship is much stronger for the DOC group than for the DMC group. 
Table 6. Descriptive statistics for the language analytic ability test

\begin{tabular}{lllll}
\hline Correction type & M & SD & Min & Max \\
\hline DMC group & 6.97 & 1.94 & 3 & 11 \\
DOC group & 8.10 & 1.63 & 3 & 12 \\
Control group & 7.41 & 2.33 & 2 & 12 \\
\hline
\end{tabular}

Table 7. Correlations between the posttests scores and language analytic ability test scores

\begin{tabular}{llll}
\hline \multirow{2}{*}{ Posttests } & & \multicolumn{2}{l}{ Scores in language analytic ability test $(r)$} \\
\cline { 3 - 4 } & & DMC & DOC \\
\hline \multirow{2}{*}{ Total } & Posttest 1 & .192 & .141 \\
& Posttest 2 & .283 & $.404^{*}$ \\
\hline \multirow{2}{*}{ Picture-cued writing test } & Posttest 1 & .151 & $.408^{*}$ \\
& Posttest 2 & .309 & $.383^{*}$ \\
\hline \multirow{2}{*}{ Error correction test } & Posttest 1 & .212 & .044 \\
& Posttest 2 & .230 & $.371^{*}$ \\
\hline
\end{tabular}

Note. ${ }^{*} p<.05$.

\subsection{Summary of the Results}

In sum, the results vis-a-vis the research questions are presented as follows:

$R Q$ 1: Does written CF have an effect on Chinese learners' acquisition of explicit and implicit knowledge of English articles?

As for the error correction and picture-cued writing tests, both treatment groups performed much better than the control group in Posttest 1 and 2, suggesting that written CF can facilitate the acquisition of implicit as well as explicit knowledge.

$R Q$ 2: Is there any difference in the efficacy that direct-only correction (DOC) and direct metalinguistic correction (DMC) have on L2 acquisition of explicit and implicit knowledge of English articles?

In the case of the error correction test, no significant difference was found between the two treatment groups in either Posttest 1 or Posttest 2, indicating that the two CF strategies had the same effects on the development of explicit knowledge. As for the picture-cued writing test, the DMC group outperformed the DOC group in Posttest 1, suggesting that the DMC was superior to the DOC on short-term improvement of implicit knowledge.

$R Q$ 3: To what extent does learners' language analytic ability mediate the effectiveness of the two written CF options?

In this study, students' posttests scores were positively related with their language analytic ability scores for the DOC group but not for the DMC group, suggesting that language analytic ability mediated the effectiveness of the DOC rather than that of the DMC.

\section{Discussion}

The study had three main purposes - to investigate the effect of written CF on the development of learners' explicit and implicit L2 knowledge, to compare the direct-only correction and direct metalinguistic correction, and to examine the extent to which learners' language analytic ability mediated the effectiveness of the two written CF strategies.

In the case of the first purpose, the results indicate that both the DOC and the DMC had an effect on scores in the error correction test and on accuracy in new pieces of writing. Thus it is suggested that written CF had effects on both explicit and implicit L2 knowledge of English articles. This finding is consistent with the results of some previous studies (e.g. Bitchener, 2008; Bitchener et al., 2005; Bitchener \& Knoch, 2008) that found the effect of written CF on improving learners' accuracy of article use in writing task without time limit which is thought to mainly elicit learners' explicit knowledge. So this study provides further evidence for the positive role of written $\mathrm{CF}$ in facilitating development of explicit knowledge. 
However, contrary to some theorists' claim that explicit intervention like CF can only foster the development of explicit knowledge but has no effect in improving implicit knowledge (e.g., Truscott, 1996), the current study found that written CF can also facilitate the acquisition of implicit knowledge. This finding lends support to R. Ellis' (1994) and N. Ellis' (2006) claims that explicit knowledge provided through explicit intervention like written CF can assist the development of implicit knowledge by promoting "noticing" and "noticing the gap" (Schmidt 1994), and such effect is not only significant but also can be sustained over time. It is generally assumed that learners need to be drawn to linguistic forms so as to be able to make progress in their well-formed L2 use (Ellis, 2005; Norris \& Ortega, 2003). Written CF helps learners to notice gaps between the target language and their output, to analyze those mismatches, and to make repairs not only to their immediate output but to their still-developing language knowledge.

The second purpose was to compare the differential effects of two direct written CF options (i.e., the DOC and the DMC) on the development of explicit and implicit knowledge. The results indicate that the two CF types had the same effects on the development of explicit knowledge, which corroborates the findings of some previous studies (e.g., Bitchener, 2008; Bitchener \& Knoch, 2008, 2010). Learners in the current study learn English in Chinese EFL context where explicit grammar instruction is applied in daily teaching and learning, so they might have been familiar with the grammatical rules of the two functional uses of English articles, though they cannot automatize their uses yet. To put it another way, learners had had explicit knowledge of English articles before they were treated in this study. Consequently, we would suggest that the function of written CF provided to them is just to activate their existing explicit knowledge. The DOC and the DMC both included correct forms which were capable enough of arousing learners' attention and then activating their existing explicit knowledge of English articles, hence the provision of additional metalinguistic information as given in the DMC did not make much difference in fostering learners' explicit knowledge. As a result, the DOC and the DMC benefited explicit knowledge to the same extent.

In terms of implicit knowledge, the results indicate that the two written CF strategies differed in effects: the DMC was superior to the DOC in the short-term. To put it another way, direct correction with metalinguistic comments had a significantly positive effect on immediate learning but its effect wore off over time. It is generally assumed that implicit knowledge once developed is not easily forgotten, so if the metalinguistic information had had an effect on learners' implicit knowledge, the effect should have been durable. Thus, it's reasonable to draw a conclusion that metalinguistic information in this study had no effect on the acquisition of implicit knowledge.

The third purpose was to examine to what extent the language analytic ability might influence the effects of two written CF options. The study showed that learners' language analytic ability mediated the effectiveness of the DOC but not that of the DMC. This finding differs from Sheen (2007) which found that the mediating effect of language analytic ability was greater for the DMC than for the DOC. Nonetheless, the current finding confirmed our assumption. The DMC in the study provided learners with additional metalinguistic information on the use of English articles, which can make up for the lack of ability in inducing linguistic rules for analytically weak learners, thus assisting them in mastering the uses of English articles efficiently. Therefore, it can be argued that analytically weak learners can benefit from the DMC to the same extent as analytically strong learners. In contrast, the DOC did not provide metalinguistic explanation, hence learners had to utilize their language analytic ability to infer and generalize the grammatical rules of English articles. As a consequence, analytically strong learners in the DOC group can benefit more from the written CF than analytically weak learners.

\section{Conclusion}

Truscott (1996) argued that error correction might have an effect on learners' explicit knowledge but might not contribute to implicit knowledge. This study showed that both the DOC and the DMC had effects on learners' explicit and implicit knowledge. Thus, the current findings refute Truscott's claim. This study also found that learners' language analytic ability mediated the effectiveness of the DOC rather than that of the DMC, which does not support Sheen's (2007) claim.

The current findings have both theoretical and pedagogical implications. Theoretically, the study contributes to the discussion on the role of explicit form-focused instruction in the form of written $\mathrm{CF}$ in facilitating the acquisition of implicit knowledge, which further contributes to the discussion of the interface between explicit and implicit knowledge. Pedagogically, the current findings indicate that the provision of written $\mathrm{CF}$ in reviewing learners' texts is necessary and effective, and teachers should not hesitate to provide written CF in English (writing) teaching so as to draw learners' attention to the gaps between their interlanguage and the target language, which may promote language acquisition. Moreover, for the effect of written $\mathrm{CF}$ to be maximized, it is 
essential for teachers to pay more attention to individual differences and select CF strategies based on learners' level of development.

To further the "agenda" that Polio argued, more thought needs to be given to how explicit and implicit knowledge can be measured. Although the error correction test was viewed as a valid measure of explicit knowledge, writing tasks - even when pressured and learners primarily focus on meaning - cannot afford a convincing measure of implicit knowledge because they allow for controlled processing and monitoring for accuracy (Shintani \& Ellis, 2013). Therefore, it may be necessary for future studies to make use of free oral production, which is argued to be a more valid measure of acquisition by SLA researchers, to measure implicit knowledge.

\section{Acknowledgements}

We would like to thank the anonymous reviewers for their valuable feedback. This research was supported by a grant from the China National Social Science Foundation (14CYY018), an MOE project (12JJD740006) of the Center for Linguistics and Applied Linguistics, Guangdong University of Foreign Studies, a Guangdong High-level Personnel Project (312-GK131036), and a Guangdong Philosophy and Social Science 12th Five-Year Plan Foundation (GD11YWW02).

\section{References}

Ashwell, T. (2000). Patterns of teacher response to student writing in a multiple-draft composition classroom: Is content feedback followed by form feedback the best method? Journal of Second Language Writing, 9, 227-258. http://dx.doi.org/10.1016/S1060-3743(00)00027-8

Bitchener, J. (2008). Evidence in support of written corrective feedback. Journal of Second Language Writing, 17, 102-118. http://dx.doi.org/10.1016/j.jslw.2007.11.004

Bitchener, J. (2012). A reflection on 'the language learning potential' of written CF. Journal of Second Language Writing, 21, 348-363. http://dx.doi.org/10.1016/j.jslw.2012.09.006

Bitchener, J., \& Ferris, D. R. (2012). Written corrective feedback in second language acquisition and writing. New York: Routledge.

Bitchener, J., \& Knoch, U. (2008). The value of written corrective feedback for migrant and international students. Language Teaching Research, 12, 409-431. http://dx.doi.org/10.1177/1362168808089924

Bitchener, J., \& Knock, U. (2010). The contribution of written corrective feedback to language development: A ten month investigation. Applied Linguistics, 31, 193-214. http://dx.doi.org/10.1093/applin/amp016

Bitchener, J., Young, S., \& Cameron, D. (2005). The effectiveness of different types of corrective feedback on ESL student writing. Journal of Second Language Writing, 14, 191-205. http://dx.doi.org/10.1016/j.jslw.2005.08.001

Carroll, J. B. (1981). Twenty-five years of research on foreign language aptitude. In K. C. Diller (Ed.), Individual differences and universals in language learning aptitude (pp. 83-118). New York: Newbury House.

Chandler, J. (2003). The efficacy of various kinds of error feedback for improvement in the accuracy and fluency of L2 student writing. Journal of Second Language Writing, 12, 267-296. http://dx.doi.org/10.1016/S1060-3743(03)00038-9

Ellis, N. (2005). At the interface: Dynamic interactions of explicit and implicit language knowledge. Studies in Second Language Acquisition, 27, 305-352.

Ellis, N. (2006). Selective attention and transfer phenomena in L2 acquisition: Contingency, cue competition, salience, interference, overshadowing, blocking, and perceptual learning. Applied Linguistics, 27, 164-194. http://dx.doi.org/10.1093/applin/aml015

Ellis, R. (1993). The structural syllabus and second language acquisition. TESOL Quarterly, 27, 91-113.

Ellis, R. (1994). Implicit/explicit knowledge and language pedagogy. TESOL Quarterly, 28, 166-172.

Ellis, R. (2004). The definition and measurement of L2 explicit knowledge. Language Learning, 54, 227-275. http://dx.doi.org/10.1111/j.1467-9922.2004.00255.x

Fathman, A. K., \& Whalley, E. (1990). Teacher response to student writing: Focus on form versus content. In B. Kroll (Ed.), Second language writing: Research insights for the classroom (pp. 178-190). Cambridge: Cambridge University Press. 
Ferris, D. R. (2006). Does error feedback help student writers? New evidence on the short-and long-term effects of written error correction. In K. Hyland, \& F. Hyland (Eds.), Feedback in second language writing: Contexts and issues (pp. 81-104). Cambridge: Cambridge University Press.

Ferris, D. R., \& Roberts, B. J. (2001). Error feedback in L2 writing classes: How explicit does it need to be? Journal of Second Language Writing, 10, 161-184. http://dx.doi.org/10.1016/S1060-3743(01)00039-X

Foin, A., \& Lange, E. (2007). Generation 1.5 writers' success in correcting errors marked on an out-of-class paper. CATESOL Journal, 19, 146-163.

Krashen, S. (1982). Principles and practice in second language acquisition. Oxford: Pergamon.

Li, S. F. (2010). The effectiveness of corrective feedback in SLA: A meta-analysis. Language Learning, 60, 309-365. http://dx.doi.org/10.1111/j.1467-9922.2010.00561.x

Norris, J. M., \& Ortega, L. (2003). Defining and measuring SLA. In C. G. Doughty, \& M. H. Long (Eds.), Handbook of Second Language Acquisition (pp. 717-761). Oxford: Blackwell Publishing.

Pica, T. (1991). Foreign language classrooms: Making them research-ready and researchable. In B. Freed (Ed.), Foreign language acquisition research and the classroom (pp. 393-412). Lexington, MA: D.C. Heath.

Polio, C. (2012). The relevance of second language acquisition theory to the written error correction debate. Journal of Second Language Writing, 21, 375-389. http://dx.doi.org/10.1016/j.jslw.2012.09.004

Schmidt, R. (1994). Deconstructing consciousness in search of useful definitions for applied linguistics. Aila Review, 11, 11-26.

Schmitt, N., Dörnyei, Z., Adolphs, S., \& Durow, V. (2003). Knowledge and acquisition of formulaic sequences: A longitudinal study. In N. Schmitt (Ed.), The acquisition, processing, and use of formulaic sequences (pp. 55-86). Amsterdam: John Benjamins.

Schwartz, B. (1993). On explicit and negative data effecting and affecting competence and linguistic behavior. Studies in Second Language Acquisition, 15, 147-163. http://dx.doi.org/10.1017/S0272263100011931

Sheen, Y. (2007). The effect of focused written corrective feedback and language aptitude on ESL learners' acquisition of articles. TESOL Quarterly, 41, 255-283.

Sheen, Y. (2010a). Introduction-The role of oral and written corrective feedback in SLA. Studies in Second Language Acquisition, 32, 169-179. http://dx.doi.org/10.1017/S0272263109990489

Sheen, Y. (2010b). Differential effects of oral and written corrective feedback in the ESL classroom. Studies in Second Language Acquisition, 32, 201-234. http://dx.doi.org/10.1017/S0272263109990507

Shintani, N., \& Ellis, R. (2013). The comparative effect of direct written corrective feedback and metalinguistic explanation on learners' explicit and implicit knowledge of the English indefinite articles. Journal of Second Language Writing, 22, 286-306. http://dx.doi.org/10.1016/j.jslw.2013.03.011

Skehan, P. (1998). A cognitive approach to language learning. Oxford: Oxford University Press.

Truscott, J. (1996). The case against grammar correction in L2 writing classes. Language learning, 46, 327-369. http://dx.doi.org/10.1111/j.1467-1770.1996.tb01238.x

Truscott, J. (1999). The case for "The case against grammar correction in L2 writing classes": A response to Ferris. Journal of Second Language Writing, 8, 111-122. http://dx.doi.org/10.1016/S1060-3743(99)80124-6

Truscott, J. (2004). Evidence and conjecture on the effects of correction: A response to Chandler. Journal of Second Language Writing, 13, 337-343. http://dx.doi.org/10.1016/j.jslw.2004.05.002

Truscott, J. (2007). The effect of error correction on learners' ability to write accurately. Journal of Second Language Writing, 16, 255-272. http://dx.doi.org/10.1016/j.jslw.2007.06.003

Truscott, J. (2010). Some thoughts on Anthony Bruton's critique of the correction debate. System, 38, 329-335. http://dx.doi.org/10.1016/j.system.2010.03.014

Truscott, J., \& Hsu, A. Y. P. (2008). Error correction, revision, and learning. Journal of Second Language Writing, 17, 292-305. http://dx.doi.org/10.1016/j.jslw.2008.05.003

Williams, J. (2012). The potential role(s) of writing in second language development. Journal of Second Language Writing, 21, 321-331. http://dx.doi.org/10.1016/j.jslw.2012.09.007 


\section{Note}

Note 1. An English proficiency test, namely the Oxford Quick Placement Test (2001) was administered to participants. A one-way ANOVA revealed that there was no significant difference in the test scores among the three classes, $F(2,89)=0.303, p>.05$, and they were all at the low-intermediate level.

\section{Copyrights}

Copyright for this article is retained by the author(s), with first publication rights granted to the journal.

This is an open-access article distributed under the terms and conditions of the Creative Commons Attribution license (http://creativecommons.org/licenses/by/3.0/). 